\title{
THE ROLE OF ALTIMETRY IN COASTAL OBSERVING SYSTEMS
}

\author{
Paolo Cipollini $^{(1)}$, Jérôme Benveniste ${ }^{(2)}$, Jérôme Bouffard ${ }^{(3)}$, William Emery ${ }^{(4)}$, Luciana Fenoglio-Marc ${ }^{(5)}$, \\ Christine Gommenginger ${ }^{(1)}$, David Griffin ${ }^{(6)}$, Jacob Høyer ${ }^{(7)}$, Alexandre Kurapov ${ }^{(8)}$, Kristine Madsen ${ }^{(9)}$, \\ Franck Mercier $^{(10)}$, Laury Miller ${ }^{(11)}$, Ananda Pascual ${ }^{(3)}$, Muthalagu Ravichandran ${ }^{(12)}$, Frank Shillington ${ }^{(13)}$, \\ Helen Snaith $^{(1)}$, P. Ted Strub ${ }^{(8)}$, Doug Vandemark ${ }^{(14)}$, Stefano Vignudelli ${ }^{(15)}$, John Wilkin ${ }^{(16)}$, \\ Philip Woodworth ${ }^{(17)}$, Javier Zavala-Garay ${ }^{(16)}$ \\ ${ }^{(1)}$ National Oceanography Centre, Waterfront Campus, European Way, Southampton SO14 3ZH, United Kingdom \\ cipo@noc.ac.uk; cgl@noc.ac.uk; hms@noc.ac.uk \\ (2) European Space Agency/ESRIN (European Space Research Institute), Via Galileo Galilei, Casella Postale 64, \\ I-00044 Frascati, Italy, Jerome.Benveniste@esa.int \\ (3) Institut Mediterrani d'Estudis Avançats, C/Miquel Marquès, 21,07190 Esporles, Spain, jerome.bouffard@uib.es; \\ ananda.pascual@uib.es \\ (4) University of Colorado, Boulder, CO 80309-0429, USA, emery@ colorado.edu \\ ${ }^{(5)}$ Darmstadt Univ. of Technology, Petersenstrasse 13, D-64287 Darmstadt, Germany, fenoglio@ipg.tu-darmstadt.de \\ (6) CSIRO (Commonwealth Scientific and Industrial Research Organisation) Marine and Atmospheric Research, \\ Castray Esplanade, Hobart Tas 7000, Australia, David.Griffin@csiro.au \\ (7) Danish Meteorological Institute, Lyngbyvej 100,2100 Kobenhavn, Denmark, jlh@dmi.dk \\ ${ }^{(8)}$ COAS (College of Oceanic and Atmospheric Sciences), Oregon State University, 104 COAS Admin. Bldg, Corvallis, \\ OR 97331-5503,USA, kurapov@coas.oregonstate.edu; tstrub@coas.oregonstate.edu \\ ${ }^{(9)}$ Univ. Copenhagen \& Danish Meteorological Institute, Lyngbyvej 100, 2100 Kobenhavn, Denmark, ksm@fys.ku.dk \\ ${ }^{(10)}$ Collecte Localisation Satellites, Rue Hermès, Parc Tech. du Canal, 31520 Ramonville St. Agne, France, \\ fmercier@cls.fr \\ ${ }^{(11)}$ Laboratory for Satellite Altimetry, NOAA (National Oceanic and Atmospheric Administration), 1335 East West \\ Hwy, Silver Spring MD 20910-3226, Laury.Miller@noaa.gov \\ ${ }^{(12)}$ Indian National Centre for Ocean Info. Services, P.B. 21, IDA Jeedimetla P.O, Hyderabad, 500055 India, \\ ravi@incois.gov.in \\ ${ }^{(13)}$ Dept. Oceanography, Univ. Cape Town, Priv. Bag X3, Rondebosch, Cape Town, 770, South Africa, \\ Frank.Shillington@uct.ac.za \\ (14) OPAL (Ocean Process Analysis Laboratory), University of New Hampshire, 39 College Rd., Durham, NH 03824, \\ USA, doug.vandemark@unh.edu \\ ${ }^{(15)}$ Istituto di Biofisica, Consiglio Nazionale delle Ricerche, Via Moruzzi 1, I-56100 Pisa, Italy, vignudelli@pi.ibf.cnr.it \\ ${ }^{(16)}$ Rutgers University, 71 Dudley Road, New Brunswick, NJ 08901, USA, wilkin@ marine.rutgers.edu; \\ ${ }^{(17)}$ National Oceanography Centre, J. Proudman Bldg, 6 Brownlow St., Liverpool L3 5DA, United Kingdom, \\ plw@pol.ac.uk
}

\begin{abstract}
The last few years have witnessed the foundation and development of a new discipline, coastal altimetry, and the coalescence of an active community of researchers who are now enthusiastically developing the topic. In the present community white paper, we summarize the technical challenges that satellite altimetry faces in the coastal zone, and the research that is currently being carried out to overcome those challenges. We introduce the new coastal altimetry data that are becoming available, and describe how we can calibrate/validate those data. Then we show several of the possible applications of coastal altimetry and conclude by looking at the future of the discipline, and at how we can build capacity in coastal altimetry.
\end{abstract}

\section{INTRODUCTION}

Satellite altimetry over the open ocean is a mature discipline, and data are routinely assimilated for operational applications. In contrast, global altimetry data collected over the coastal ocean remain largely unexploited in the data archives, simply because intrinsic difficulties in the corrections (especially the wet tropospheric component, the high-frequency atmospheric and oceanic signals and the tides) and issues of land contamination in the footprint have so far resulted in systematic flagging and rejection of these data, leaving 'gaps' in the coastal zone. In the last couple of years, considerable research has been carried out into overcoming these problems and extending the capabilities of current and future altimeters as close as possible to the coast, with the ultimate aim to integrate the altimeter-derived measurements of sea level, wind speed and significant wave height into coastal ocean observing systems. At the same time, the major Space Agencies have recognized the importance of the topic and are sustaining coastal altimetry research through dedicated projects. This new "coastal altimetry" 
community, inherently interdisciplinary, has already had four well-attended international workshops (see http://www.coastalaltimetry.org), and produced a book on the subject [1]. The first custom-processed coastal altimetry data are now available, and many more data from Jason-1, Jason-2 and Envisat will become available in the near future. Eighteen years of coastal zone data from various past and present altimetric missions are waiting to be reprocessed, we could almost say rediscovered, to describe the status of the entire world's coastal zone, a region of vital interest for human society and sustainable development, including many stretches where a space-borne altimeter provides the only measurement device.

Filling the aforementioned gaps in the coastal zone would provide current and wave observations for erosion and sediment transport studies, ship routing and coastal defence design and operation, and would help to monitor surges and to measure long-term coastal sea level change. Other applications include fisheries, search and rescue, and the movement of hazardous spills, pollution and harmful algal blooms. In all of these cases, the availability of reprocessed altimeter data and their assimilation into models alongside sea surface temperature (SST) and data from research vessels and ships of opportunity, moorings, wave buoys, tide gauges, gliders and HF (High Frequency) radars has the potential to increase the realism and accuracy of the predictions.

In this community white paper, after a brief review of the challenges in coastal altimetry and description of the new products, we illustrate (with the aid of some application examples) how the new products can be used, and we discuss the plans for further integration of this novel data source into the coastal observing systems.

\section{CHALLENGES IN COASTAL ALTIMETRY}

A number of challenges remain in the processing of the altimetric waveforms in the coastal zone and in the correction of the measurements for path delay and geophysical effects (tides and atmospheric). These were first identified and described in the summary of the first Coastal Altimeter Workshop [2] and the improvements were reviewed at the second Altimetry Workshop [3]. In summary:

- Retracking is needed to recover the sea surface height (SSH) signal in the 'last $10 \mathrm{~km}$ ' next to the coast. Specific coastal retrackers, subject of ongoing research, should give better accuracy \& precision than generic deep ocean retrackers. Contamination effects on waveforms due to land and bright targets might be predicted in some places using detailed coastlines and digital elevation models (DEMs).
- Farther from the coast, the wet tropospheric correction is a main source of error. Strong gradients in water vapour across atmospheric fronts near land produce changes in path delay equivalent to several cm over $20-50 \mathrm{~km}$, which must be corrected. Several methods are being developed, with encouraging results: (I) dynamic extrapolation methods, using high-resolution atmospheric models; (II) GNSS (Global Navigation Satellite Systems) measurements of ZTD (Zenith Total Delay) (and meteorological correction to ZWD - Zenith Wet Delay); (III) decontamination of the land effects, based on detailed DEMs and/or statistical approaches relying on inherent inter-channel correlation for mixed ocean/land pixels; (IV) retrieval of integrated water vapour from infrared imagery, with inherent $1-\mathrm{km}$ resolution.

- For those applications needing the removal of tidal and atmospheric signals, large errors in tidal models and in the models used to obtain HF and inverse barometer corrections remain a problem. These models are improving, but require detailed coastal bathymetry with horizontal resolutions of at least 1 $\mathrm{km}$ (preferably $200 \mathrm{~m}$ ), from the $200 \mathrm{~m}$ isobaths to the coast.

- The ionospheric delay correction is affected when the C-band (or S-band) footprint of the altimeter "sees" the coast (prior to the Ku-band).

- The sea state bias correction is also a concern, although not the greatest error source, and a thorough comparison against coastal wave measurements and models is needed.

For all those applications requiring the retrieval of absolute dynamic topography and absolute geostrophic currents from altimetric data in coastal areas, there is an additional crucial challenge, i.e. the estimation of an accurate and high resolution coastal Mean Dynamic Topography (MDT).

\section{INITIATIVES AND NEW PRODUCTS}

The importance of coastal altimetry has been recognized by the major Space Agencies, which are supporting research and development in the field. The European Space Agency (ESA) is funding the COASTALT (Coastal Altimetry) Project (http://www.coastalt.eu) aiming at defining and developing a prototype software processor for Envisat and testing it over a few pilot areas surrounding Europe. Ultimately, the plans are for ESA to routinely generate and distribute these new Envisat coastal altimetry products globally. In France, the Centre National d'Études Spatiales (CNES) is funding the PISTACH (Prototype Innovant de Système de Traitement pour les Applications Côtières et l'Hydrologie) Project for the reprocessing of the global Jason-2 altimeter records in the coastal zone. This 
project takes advantage of the improved performances of Jason-2 near the coasts to give access to high-resolution $(20 \mathrm{~Hz}$ i.e. $\sim 350 \mathrm{~m}$ ) along-track altimetric measurements, with an ensured continuity from the open ocean up to the shoreline. These data, now freely accessible via FTP from ftp://ftpsedr.cls.fr/pub/oceano/pistach/ allow a finer description of short scale $(5-20 \mathrm{~km})$ coastal phenomenon such as river plumes, coastal upwelling and circulation, with the most significant gain with respect to classical $1-\mathrm{Hz}$ Level-2 altimetry products expected to be a better representation of local gradients and hence currents. Higher-level along-track altimetry products (e.g. regional MERSEA (Marine Environment and Security for the European Area) product over the Gulf of Mexico or North-East Atlantic) will also directly benefit from the PISTACH products if they are used as input. CNES and the U.S. National Aeronautics and Space Administration (NASA) are also funding a number of projects related to coastal altimetry within the OST-ST (Ocean Surface Topography Science Team) framework.

The development of coastal altimetry and its application to current and future missions adds to the increasing need for harmonised products across all available data. Modern computing resources have allowed lesscompact formats to be introduced, like NetCDF (Network Common Data Form), which is selfdescribing, allowing products to be very flexible in content. As this format becomes more accepted across the climate community, standards have evolved for variable naming and links between measurement data and their associated errors and quality control information. The introduction of these standards allows development of more generic software solutions, giving access to the data for non-specialists. Coastal altimetry does not, of itself, impose any additional constraints on the development of data products. However, the coastal application of data has two key drivers that should reinforce existing developments. The first is that the wide range of potential corrections, auxiliary data and processing required for the extended range of potential applications and more complex geophysical coastal processes make the inclusion of more complete metadata a higher priority. This is being addressed by new coastal products with their full gamut of descriptive metadata included in the NetCDF format. The second driver is that users will be less reliant on altimetry as their primary data source, and hence be more reluctant to invest large amounts of time in developing their systems to incorporate these, potentially complex, new products. This is increasing the move away from fixed products towards tools and services to generate customized products, on demand. These services can tailor products to the required application and region, at the time of generation, increasing the uptake of altimetry by operation users, important for continuation of altimetry missions.

\section{CALIBRATION AND VALIDATION}

The challenges outlined above call for a comprehensive validation and intercalibration of both coastal altimetry and other observational data dedicated to coastal ocean studies. The first step consists in implementing the existing technological advances in satellite altimetry in the coastal area. This is part of an ongoing work carried out by several groups, as in the aforementioned COASTALT and PISTACH projects. In a second step, improved altimetry measurements must be compared with independent observing systems at several temporal and spatial scales. There is consensus that the so far unexploited capabilities arising from the merging of existing in situ (glider, tide gauges, drifters) data sources with remote sensing data (SST, altimetry) have to be developed in a calibration-validation environment, where the understanding of the physical contents of each sensor is thoroughly investigated by comparing altimetry with other kinds of data. As an example, Fig. 1 shows some results from an intensive observational program in the Western Mediterranean carried out by the Institut Mediterrani d'Estudis Avançats (IMEDEA) by running coastal glider missions along selected Envisat and Jason-1/2 altimeter tracks. The goal of this experiment is threefold: i) to investigate the limitations and potential improvements of altimetry data in the coastal area ii) to test the feasibility of new technologies to study coastal dynamics and iii) to understand the physical content of each dataset. The first results show good agreements and are encouraging. 


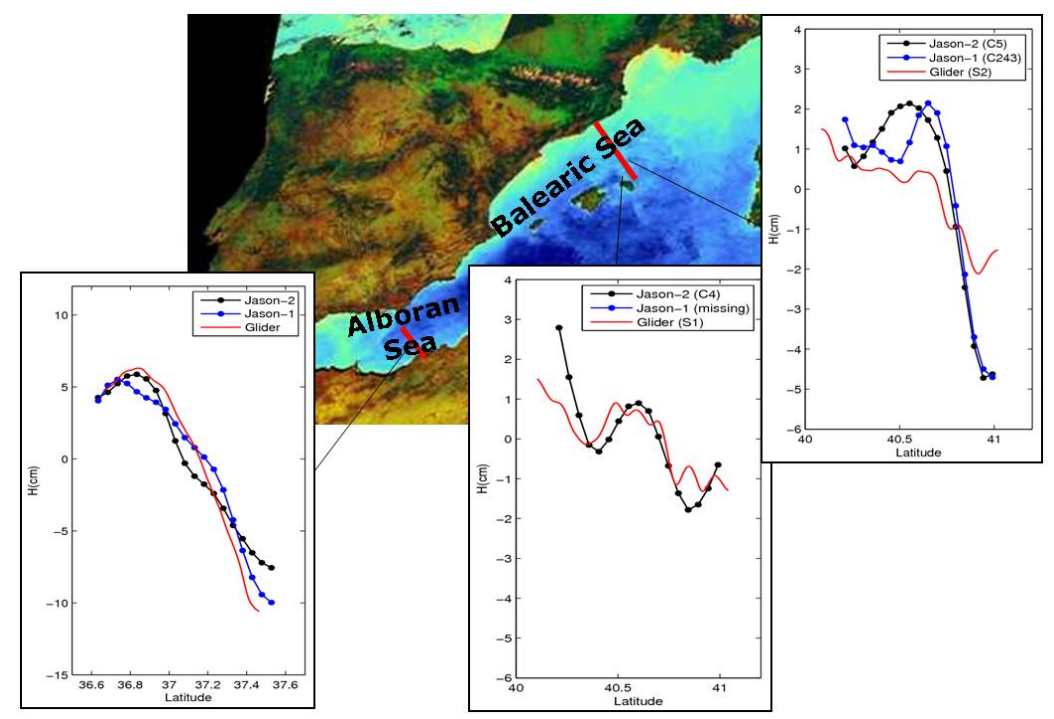

Figure 1. Along track absolute dynamic topography from JASON-1 and JASON-2 altimeters and dynamic height from glider data for the Alboran Sea [4] and Balearic Sea [5] in the Western Mediterranean. For the Balearic Sea, both the onward (left) and return (right) legs of the glider are shown. Absolute dynamic topography is computed by adding to the along track SSH anomalies a Mean Dynamic Topography [6]. Dynamic height is obtained from the glider pressure, temperature, and salinity profiles with a reference level of $180 \mathrm{~m}$.

\section{SYNERGY OF COASTAL ALTIMETRY AND OTHER DATASETS}

Dynamics along the continental slopes, over the shelf and in the coastal areas are difficult to observe given the wide spectrum of temporal and spatial variability of the various physical processes (coastal currents, eddies, meanders, filaments, small-scale convection, coastal trapped waves, etc.). Studying such complex dynamics requires the development of synergistic approaches through the combined use of modelling and observing systems at several spatial/temporal sampling levels. Satellite altimeters provide sustained observations of phenomena often unachievable by other means. But after the along-track SSH data have been successfully retrieved, a second set of issues relate to how the information is used. Does one use the more basic and higher resolution SSH data along the tracks? Or does one attempt to produce two-dimensional horizontal maps of SSH? Both space and time scales decrease in the coastal ocean as one approaches land. Given the distance between tracks and the time between repeats, traditional nadir altimeter data will never resolve the scales $(10+\mathrm{km}$ and $1+$ day) of the variability in coastal currents and SSH fields through even the most sophisticated "gridding" techniques. This remains true for multiple (up to 4) altimeters and even for proposed swath altimeters, which will have high spatial resolution but infrequent (5-days or longer) repeat coverage. The result is a need to combine the information from altimeters with that from other satellites (individual or sequences of SST and colour fields, when clouds allow), land-based radars (for surface currents within 50-150 $\mathrm{km}$ of land) and in situ measurements (moorings, gliders, drifters, ship surveys and tide gauges). Even if altimeters were capable of providing continuous highresolution fields of SSH, other means would be needed to observe the highly baroclinic subsurface fields. Thus, altimetry must be considered as one part of Integrated Ocean Observing Systems (IOOS), which should also include regional hydrodynamic modelling of shelves and coastal circulation. This new approach is being increasingly adopted. For instance, for the coastal ocean bordering European seas we can cite several studies:

- combining altimetry and models, for example as in [7] and [8] through comparison experiments respectively over the Mediterranean and Atlantic coastal zone;

- combining altimetry and in-situ data, for example as in [9], [10] and [11]; studies using both mooring and altimetry data to monitor a narrow coastal current; monitoring of coastal dynamics by using gliders and altimetric data [4] and [5];

- combining altimetry and SST like in [12] who show the feasibility of monitoring coastal processes such as current intrusion over the continental shelf of the Gulf of Lion; or like in [13] who investigated eddy generation;

- using in situ, remote-sensing and modelling together: reference [14] recently demonstrated the possibility of monitoring of deep water formation from space in this way.

For the applications requiring absolute currents and therefore a coastal MDT, the synergy must include gravity missions as GRACE (Gravity Recovery And 
Climate Experiment) and GOCE (Gravity and Steady State Ocean Circulation Explorer). However, as the resolution from these missions is not sufficient per se, a strong synergy is also expected between, altimetry, GRACE and GOCE data and in-situ gravimetric measurements (shipborne/airborne) to enhance the resolution of the geoid, and therefore the MDT regionally.

\section{APPLICATIONS OF COASTAL ALTIMETRY}

Some of the uses of coastal altimetry have already been mentioned, and current and future applications have also been indicated by the user community in a recent survey carried out by PISTACH and COASTALT. At the most general level, we can say that the SSH, wave and wind information about the coastal and shelf region can help monitoring surges, long term coastal sea level variations, erosion and sediment transport studies, ship routing, fisheries, search and rescue, and the movement of hazardous spills, pollutants and harmful algae blooms. Here we provide more details on the full range of possible applications, illustrating them with examples where possible.

\subsection{Sea Level and Tides}

The quintessential most immediate application of coastal altimetry is to monitor coastal sea level. This has three interrelated aspects: short term sea level variations (leading to monitoring of surges), long-term sea level change due to climate change, and tides.

A good example of a statistical model which combines satellite and tide gauge observations through a multivariate regression analysis is the one set up to study the near real time SSH variability in the North Sea and Baltic Sea, with focus on storm surges in coastal regions [15]. The model has been run for test cases (Fig. 2) and shows a performance comparable to stateof-the-art hydrodynamic models when estimating the near real time SSH. It is planned to implement it operationally for real-time storm surge predictions, including Jason-2 observations.

This type of modelling will greatly benefit from qualitycontrolled coastal altimetry, because it will allow resolving near coastal processes. For the North Sea area this is particularly important, as the SSH signals tend to travel as Kelvin waves along the coast, with exponentially decreasing amplitude away from the coast. For island filled areas, such as the Inner Danish Waters, a high return of good quality data is essential for the use of the satellite altimetry. Even if one considers the difficulties of assimilation (getting good quality near-real time data, determining covariances, handling the space-time sampling) which might hamper the full adoption of coastal altimetry for near-real time surge studies, the new products should at least provide an independent data set that can be used for offline surge model validation, in combination with an accurate coastal tide model.

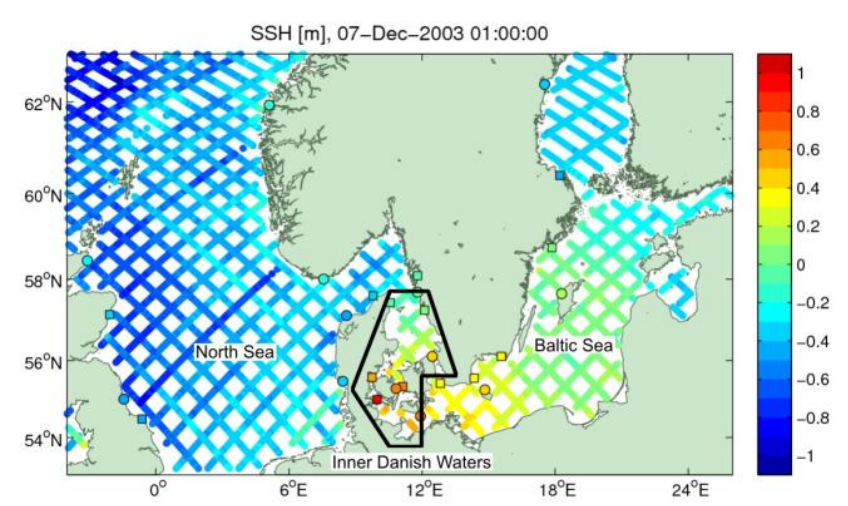

Figure 2. An example of the model performance for the storm surge of December 7, 2003 in the Inner Danish

Waters. The dots indicate the predictions of the statistical model. Observations from tide gauges used in the model are marked by circles, observations from tide gauges not used in the model are marked by squares, and can be used for model validation.

A long record of quality-controlled coastal data is also of great value at a time of increasing focus on mean sea level (MSL) and the impact of sea level change. A high quality global coastal dataset will allow for local sea level trend determination. There are two particular instances in which MSL studies could benefit from coastal altimetry. One is where there are coastal dynamical effects resulting in different signatures of MSL variability and trends at the coast and farther offshore. The availability of altimetry closer to the coast will provide data sets with which to connect the coastal tide gauge data to the offshore altimeter data. Another application is in altimeter calibration by means of tide gauges, an important method used to calibrate TOPEX/Poseidon, Jason-1 and -2 and ESA missions. By providing data closer to the gauge, concerns about tidal and other variability in the intervening distance from ground track to tide gauge will be reduced, as this variability can be better estimated.

The liaison between altimetry and tidal science is a good example of give and take; if on one side altimetry is calibrated with tide gauges, on the other it provides crucial data for tidal models. Reference [16] describe well the difficulties in deriving accurate coastal tide models given the present space-time sampling of altimetry, but with the new coastal altimetry products, the next generation of altimeters (including delayDoppler and wide swath instruments) and advanced assimilation techniques, significant improvements in coastal models will be possible. A key role that coastal IOOS may play to aid coastal altimetry would be in the deployment of a limited number of long-time series bottom pressure measurements along the shelf. These 
data would support the refinement of shallow sea and coastal margin tidal models, making it possible to more accurately de-tide the coastal altimeter SSH.

\subsection{Assimilation in 3-D circulation models}

Perhaps the most ambitious application of the surface dynamic topography from coastal altimetry is to estimate and forecast the three-dimensional ocean state through data assimilation. A good case in point is the work by the Ocean Modeling group at Rutgers University on variational data assimilation in the Regional Ocean Modeling System (ROMS). Observations assimilated are satellite along-track SSH anomalies, SST, HF radar surface currents, and subsurface temperature and salinity from ships, autonomous underwater vehicles and/or profiling floats, as part of the Mid-Atlantic Regional Coastal Ocean Observing System (MARCOOS). The dominant circulation in the Mid-Atlantic Bight (MAB) has short, anisotropic scales due to the shelf-slope front along the continental shelf-break, a significant Slope Sea gyre circulation, and Gulf Stream (GS) warm core ring interactions with the shelf-slope front that drive episodic exchanges of coastal and deep ocean waters. The variational approach allows combining data from multiple satellites and in situ observing systems with the model physics, therefore introducing dynamic and kinematic constraints into the analysis. The resulting analyses will then be used for diagnostic studies of the area and for predictability studies. Work is also underway to incorporate real time data in the assimilation system for operational prediction.

Realizing that satellite data is the only source of information in real time in many parts of the world ocean, including some parts of the US east coast, the Rutgers group has developed methodologies that correctly exploit the information content in remotely sensed observations. The hydrographic in-situ observations are then used to evaluate the quality of the inversion. In the deep ocean (GS and Slope Sea area) the two main sources of satellite information, namely SST and SSH, are found to be highly complementary and therefore both need to be assimilated in order to obtain the correct 3-dimensional structure of the ocean. The assimilation system can also correct for biases in the model estimate due mainly to strong biases present in the global ocean models that are used to force ROMS. Future work on the analysis/forecast system will be to evaluate a reprocessed coastal altimeter data stream derived using de-aliasing corrections and other required near-coast data filtering and error-correction approaches. The resulting analyses will then be compared with the current assimilation system to evaluate to what extent reprocessed altimeter data can constrain and improve the observed dynamics. We anticipate the corrected SSH anomalies to be a valuable data set for constraining dynamics in the MAB (and many other coastal regions). When applied in the full domain (coastal zone and adjacent deep ocean) the altimeter data could help to constrain the along- and across-shelf pressure gradients that are fundamental to the shelf circulation, shelf/slope front, and the remotely generated forcing associated with GS ring interactions.

On the U.S. west coast, modellers at Oregon State University (OSU) are also developing methods to assimilate along-track SSH anomalies into coastal circulation (non-linear ROMS) models. Their data assimilation system uses variational representer-based methods [17], incorporated into tangent linear and adjoint AVRORA codes developed at OSU. The present OSU pilot forecast model provides daily updates of 3day forecasts of SST and surface current fields, available freely over the web (http://www.nanoos.org/). An example application for the forecast fields is their use by tuna fishers to identify frontal regions between the cooler water next to the coast and warmer offshore waters. This is preferred tuna fish habitat, with temperatures around $14^{\circ} \mathrm{C}$. The fishers then plan their cruises to reach the frontal regions using the shortest time and least fuel.
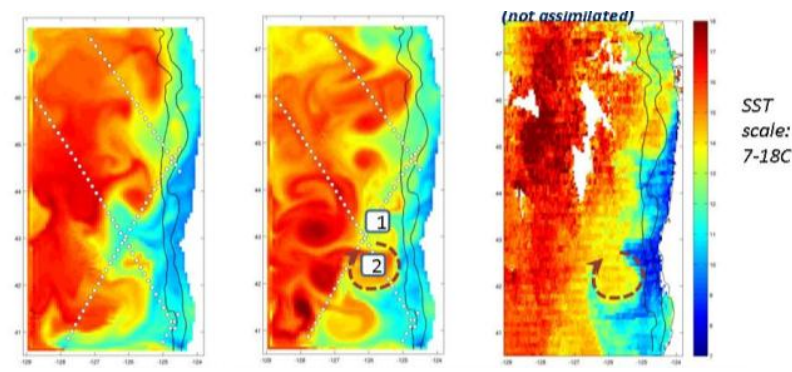

Figure 3. SST and altimeter tracks. (Left) Model SST hindcast without altimeter assimilation; (Middle) SST hindcast with altimeter assimilation; (Right) GOES (Global Earth Observation System) satellite SST field for the same day. The assimilation of the altimeter data reduces the offshore extent of the SST filament separation at $43^{\circ}-44^{\circ} \mathrm{N}(1)$ and improves the location of an anticyclonic eddy south of the filament (2), in better agreement with the satellite data.

Although altimeter data are not routinely assimilated into the forecasts, experimental hindcasts (using the methods described above) have shown that the positions of the SST fronts are improved in comparison to satellite SST fields when along-track SSH data are assimilated (Fig. 3). Since the satellite SST fields are often obscured by clouds, the altimeter data assimilation offers the most reliable source of improvements to the model SST fields. Making improved coastal along-track altimeter data available in near real time (over the past 2-6 days) for assimilation into the models would increase the realism of the predictions. 


\subsection{Coastally Trapped Dynamics}

One of the prospective applications of a global coastal altimetry dataset is to look at those peculiar manifestations of the ocean dynamics that are 'trapped' along the coast or at the shelf edge. One example are propagating coastal trapped waves identified in altimeter data along the continental slope [18], whose study could be extended over the shelf and in coastal areas. Similarly, coastal altimetry will contribute to the investigation of the dissipation (and/or reflection) mechanisms of mesoscale eddies and westwardpropagating planetary waves once they arrive on the shelf and in coastal waters.

\subsection{Wind and Waves}

Finally, there are interesting applications for the wind and wave coastal altimetry products. For instance, at the Danish Meteorological Institute, open ocean SWH (Significant Wave Height) data are currently used for validation of an operational wave model. An improved data set of significant wave height in coastal areas would allow extending the validation to those areas, which are heavy with ship traffic and vulnerable to oil spill accidents. In the meantime, one of the most advanced applications of the wind and wave data is taking place at NOAA's National Center for Environmental Prediction (NCEP). NCEP is consistently increasing its use of Jason-1, Jason-2 and Envisat altimeter data in both maritime forecasting and predictive models used for forecast guidance. A technology transfer effort funded by NASA is being used to assure that NCEP Ocean Prediction Center (OPC) forecasters now have these data displayed within 1 to 3 hours of satellite measurements. Real time altimeter wave height and wind speed data are now, or will soon be, used in sea state forecasting and analysis product generation for the US coasts and within the OPC's offshore coastal margin areas of responsibility. The NCEP Environmental Modelling Center is now assimilating all near real time SWH data into the WAVEWATCH III ocean wave model used by OPC and all US National Weather Service offices for nearshore, offshore and high sea forecast guidance. Moreover the altimeter wind speed data (because they are not assimilated into surface wind analysis products) are used as a critical independent validation of the global and coastal ocean wind speed data used to force WAVEWATCH III. Near term goals at NCEP are to provide increasingly refined coastal forecasts and model guidance, thus an emphasis on coastal altimeter SWH and wind speed data quality and validation is desirable. The present interleaved operation of the Jason-1 and Jason-2 orbits is highly attractive for all these activities.

\section{CAPACITY BUILDING IN COASTAL ALTIMETRY}

The recent development of coastal altimetry is having an additional beneficial effect in that, being related to coastal management and sustainable development, it links directly to the work of the local scientists and administrators in many of the world's regions and therefore contributes to capacity building for altimetry as a whole. Two examples of capacity building potential (in India and the Southern African countries) are illustrated below. Another notable example is in Thailand via the EU-funded GEO2TECDI project [19].

In India, coastal altimetry studies have been initiated as a joint project between the National Institute of Oceanography (NIO) and the Indian National Centre for Ocean Information Services (INCOIS), called ALTICORE-India (ALTImetry for COastal REsearch) and forming a larger collaborative effort with the European Union group ALTICORE-EU (see http://www.alticore.eu). Investigations carried under the above project are based on improvements of atmospheric and tide related correction terms along select ground tracks for various satellites, off the west coast of India, with filtering and reconstruction involving additional interpolation steps, similar to those carried out in the Corsica Channel in the Mediterranean Sea [20]. The Indian Coast lends itself well to coastal altimetry studies: reference [21] has estimated boundary currents from altimeter for the East India Coastal Current (EICC) at the western boundary of the Bay of Bengal, using experimental reprocessed TOPEX/Poseidon data for the coastal zone. Their methodology reveals the full spectrum of along-shore current, ranging from intra-seasonal to inter-annual time scales. Furthermore, it has been demonstrated using coastal altimetry that the seasonal cycle dominates the variability, but the non-annual timescales have similar energy levels all along the EICC path [22]. Following on these encouraging results, NIO and INCOIS are now planning to reprocess all the along track profiles for the Indian region with regional corrections. This new dataset, once validated with other data sets including tide gauge observations, will be assimilated into ocean circulation models for operational forecasting system of the Indian coastal seas. Furthermore, INCOIS provides operational ocean state forecast for the Indian seas using WAM/WAVEWATCH models for the coast and the open ocean. Once the coastal altimetry-derived SWH data are available, they will be assimilated for the improved forecast. The future Indian/French SARAL/Altika (Satellite with ARgos and ALtiKa) mission [23], due for launch in 2012, holds great promise to further improve the accuracy and coverage of the altimeter-derived products. 
Southern Africa is uniquely placed in the world, with an extremely energetic, warm western boundary current, the Agulhas Current System on the east coast, which can interact with an extremely energetic eastern boundary upwelling system, the Benguela Upwelling System, on the west coast. This interaction takes place over the very wide Agulhas Bank Shelf region. It should be noted that over $40 \%$ of Africa's population derives its livelihood from coastal and marine ecosystems and resources. The continent's reliance on coastal and marine resources is set to increase substantially, as coastal populations are expected to double by 2025 . Understanding the dynamics of coastal and shelf seas is thus essential for managing vulnerable coastal ecosystems, protecting lives and livelihoods, and planning sustainable development. Remote sensing in general and coastal altimetry in particular offers a powerful and cost effective means of observing the marine and coastal environment.

Five main areas of southern Africa (Fig. 4) have already been identified as good locations to make use of coastal altimetry advances [24]. These are (from west to east) the Angola-Benguela Frontal Zone (for tracking and evolution of Benguela Niños), the southern Benguela Upwelling region (for monitoring the upwelling region under climate change), the Agulhas Bank south of Africa (an important spawning region for anchovy and pelagic fish), the east coast Agulhas Current, which is an giant wave-current interaction region, and the Mozambique Channel for the impact of rising sea level and tropical storms on impoverished communities.

Numerical modelling of the coastal ocean circulation around southern Africa is at an early stage, but there have been notable successes on the west coast, and the Agulhas Bank. Advances in coastal altimetry will serve as an important set of measurements to calibrate the models (like ROMS) for current variability, and will complement significant improvements of the in situ measurement capability in the Agulhas current system [25]. Wind, SST and ocean colour are regularly being obtained from satellites at sufficiently fine scales, and being used to either force or verify numerical model studies in the coastal zone.

\section{FUTURE PLANS FOR COASTAL ALTIMETRY}

When the existing 18-year archive of altimetry data is reprocessed to enable reliable estimates of sea level and its gradient over the continental shelf, an immediate application will be the construction of a global atlas of the statistics of sea level and surface current variability over the continental shelves of the world. In situ observations are lacking or inadequate for most parts of the world for the construction of such an atlas.

As marine industries move into deeper and deeper water, interest in the statistics of currents over the outer shelf and the continental slope is increasing. But if some new industry suddenly expresses an interest in some particular location, they do not want to wait many years for a targeted observational programme to be conducted.

The only option in such cases is to rely on modelling and analysis of existing observations, which, in many cases, will comprise coastal altimetry and the trajectories of a limited number of drifting buoys.

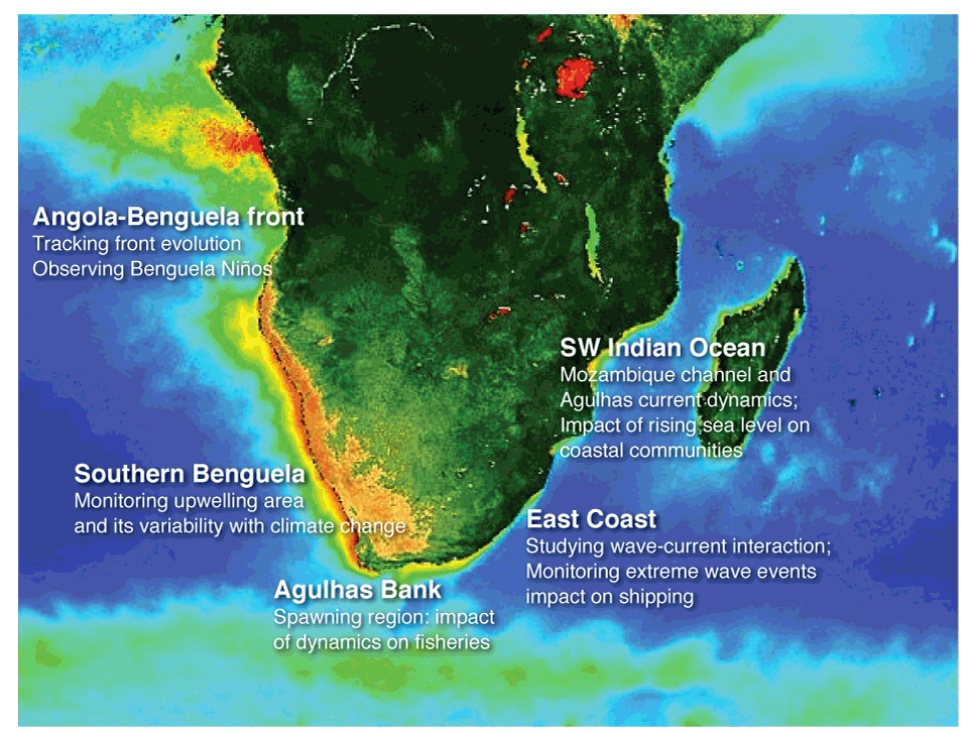

Figure 4. Pilot areas for the development of coastal altimetry around Southern Africa, with an indication of the main motivations in each area. From [24], updated. 
The energy sector is one with an increasing interest in ocean currents. For oil or gas extraction, currents represent a major threat to operational safety and they are one of the hazards, which need to be accurately evaluated, of operating in deeper water. But strong deep ocean currents can also be viewed as a potential energy resource, as tidal currents are in shallower water. The East Australian Current, for example, has core speeds estimated to be $1 \pm 0.5 \mathrm{~m} / \mathrm{s}$ in places (Fig. 5), according to ocean models [26][27]. An assessment of whether it might be economically feasible to exploit this energy resource will require detailed assessment of in situ data, augmented by an analysis of the reprocessed altimetry data. Knowledge of the statistics of the coastal wave field from long-term coastal altimetry can also be a valuable asset in this scenario.

While the widespread adoption of coastal altimetry relies on maximising the impact of the existing, 18-year long dataset in applications like those described above, the future evolution of the field appears to be tightly linked with the advent of future missions, both nadirviewing and wide-swath, which should improve both quantity and quality of coastal altimetry data. Nadirviewing altimetry is expected to make a quantum leap with the arrival of delay-Doppler instruments like those on CryoSat (launched in April 2010) and, crucially, on Sentinel-3, the operational successor of Envisat in ESA's oceanographic mission line-up.

The delay-Doppler technique [28] is a more efficient alternative to conventional altimetry, exploiting a larger share of the power in the echo returns, thus resulting in better accuracy and along-track resolution (a very useful attribute to sample short-scale features in the coastal zone). Wide swath altimetry, with missions like the Surface Water and Ocean Topography (SWOT), relies on radar interferometry principles to carry out 2-D SSH measurements at resolutions of the order of $1 \mathrm{~km}$ [29], and a large amount of research can be anticipated on how to take advantage of this technique in the coastal environment, including the benefit of deriving a highresolution slope map. Finally, improvements in the coastal geoid, expected from the merging of GRACE and GOCE data with in situ gravimetric measurements, will undoubtedly be crucial for all those applications where an absolute dynamic topography is needed.

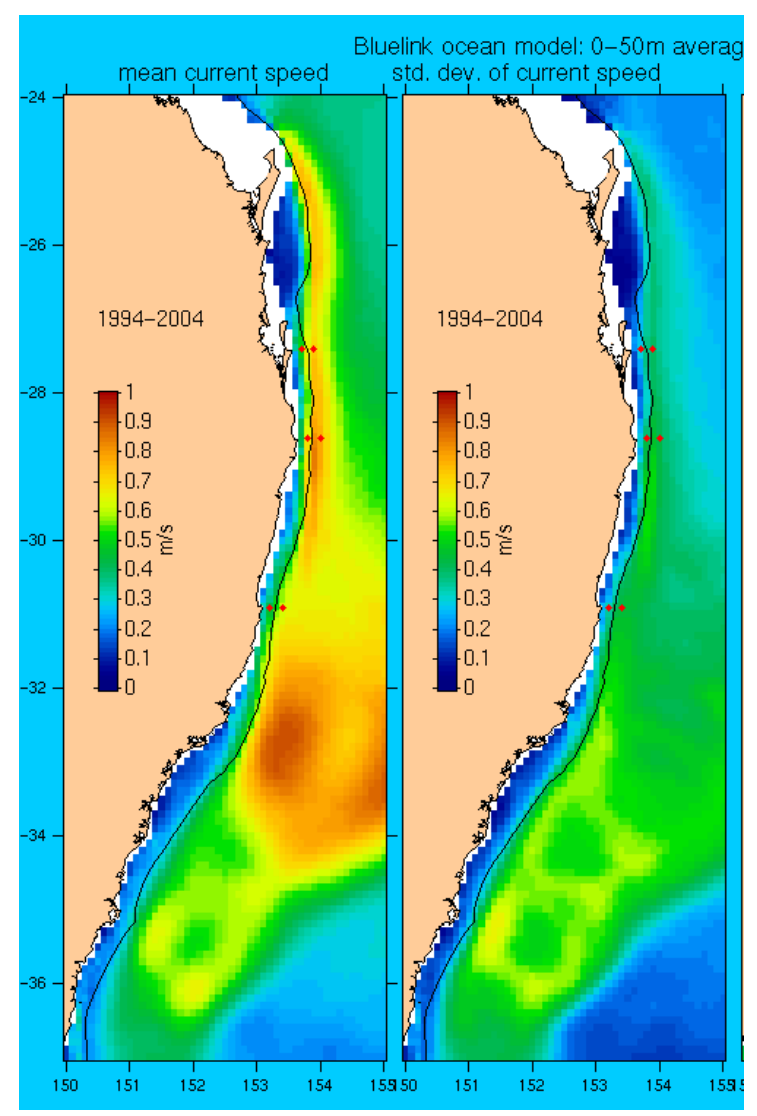

Figure 5. Mean and standard dev., over 10 years, of the near-surface (0-50m) current speed off east Australia, as estimated by an ocean model of $0.1^{\circ} \times 0.1^{\circ}$ spatial resolution. Re-processed altimetry will be used to assess the accuracy of this model, and to drive improvements.

\section{CONCLUSIONS}

This paper has examined the recent development of coastal altimetry and looked at the challenges and perspectives of this novel field. Improvements have been and are being made to processing of altimeter data and the various corrections, to bring this measurement closer to the coast. Water vapour and tidal corrections are particularly crucial, and there is a real need to increase their precision in the coastal zone. Tidally forced currents can become non-linear and difficult to forecast, so more accurate maps of detailed bottom 
bathymetry are needed. Then we need the best possible calibration/validation systems to validate the new data in the context of dramatic space/time variability in the coastal zone. Efforts in this direction are being carried out by a lively community within a number of initiatives, including the PISTACH and COASTALT projects. The new generation altimeters are designed to take up coastal dynamic topography and wave measurements that would help integrate the sea level and wind speed into coastal ocean observing systems.

Ultimately, most coastal oceanographers expect that all of the available measurements will be assimilated into operational models of the circulation and sea state (and eventually the ecosystem) to produce nowcasts and short-term (several days to several weeks) forecasts. For altimetry to play this important part in operational coastal observing/modelling systems, however, we must first overcome the present obstacles in retrieving the along-track SSH data, as described above. Data assimilation methods need both SSH values and estimates of the errors or uncertainties in those values. The research reviewed above serves as a prelude and context for the more detailed and focused efforts needed to move forward, both by promoting the long existing datasets (a real asset), and by exploiting the several forthcoming missions. There is no doubt that the new coastal altimetry products will constitute a crucial input for coastal observing systems: the experience gained in optimizing existing coastal altimetric data will guide the design of the future instruments, so that the multidecadal record is not only continued, but also improved in quality and quantity.

\section{REFERENCES}

1. Vignudelli, S., A. Kostianoy, P. Cipollini, J. Benveniste (eds.) (2011). Coastal Altimetry, Springer, doi:10.1007/978-3-642-12796-0.

2. Smith, W. H. F., T. Strub, and L. Miller (2008). First Coastal Altimetry Workshop, Eos Trans. AGU, 89(40), 380 .

3. Benveniste, J. and S. Vignudelli (2009), Challenges in Coastal Satellite Radar Altimetry, Eos Trans. AGU, 90(26), 225.

4. Ruiz S., A. Pascual, B. Garau, I. Pujol, J. Tintoré (2009). Vertical motion in the upper ocean from glider and altimetry data, Geophys. Res. Lett., 36, L14607.

5. Ruiz, S., Pascual, A., Garau, B., Fougère, Y., Alvarez, A., Tintoré, J. (2009). Mesoscale dynamics of the Balearic Front, integrating glider, ship and satellite data, J. Mar. Sys., Vol. 78, pp S3-S16.

6. Rio, M.-H., P.-M. Poulain, A. Pascual, E. Mauri, G. Larnicol (2007). A mean dynamic topography of the Mediterranean Sea computed from altimetric data and in-situ measurements. J. Mar. Sys., 65, 484-508.
7. Bouffard, J. \& Co-Authors (2008). Comparison of ocean dynamics with a regional circulation model and improved altimetry in the North-western Mediterranean. Terr. Atmos. Ocean. Sci., 19, 117-133.

8. Roblou L., Lyard F., Le Henaff M., Maraldi C. (2007). Xtrack, a new processing tool for altimetry in coastal oceans, ESA ENVISAT Symposium, Montreux, Switzerland, April 23-27, 2007, ESA SP-636.

9. Pascual, A. and Gomis, D. (2003). Use of surface data to estimate geostrophic transport. J. Atmos. Ocean. Tech., 20(6): 912-926

10. Bouffard J., S. Vignudelli, P. Cipollini, Y. Menard (2008). Exploiting the potential of an improved multimission altimetric data set over the coastal ocean, Geophys. Res. Lett., 35, L10601.

11. Le Hénaff, M., Roblou, L. and J. Bouffard (2009). Monitoring Navidad occurrences in the Bay of Biscay using coastal altimetry, submitted to Geophys. Res. Lett.

12. Bouffard J. \& Co-Authors (2011). Introduction and assessment of improved coastal altimetry strategies: case study over the Northwestern Mediterranean Sea, in Vignudelli, S., A. Kostianoy, P. Cipollini, J. Benveniste (eds.), Coastal Altimetry, Springer, doi:10.1007/978-3642-12796-0_12.

13. Pascual, A., B. Buongiorno Nardelli, G. Larnicol, M. Emelianov, and D. Gomis (2002). A case of an intense anticyclonic eddy in the Balearic Sea (western Mediterranean), J. Geophys. Res., 107(C11), 3183.

14. Herrmann, M., J. Bouffard, and K. Béranger (2009). Monitoring open-ocean deep convection from space, Geophys. Res. Lett., 36, L03606.

15. Madsen K. S., J. L. Høyer, and C. C. Tscherning (2007). Near-coastal satellite altimetry: Sea surface height variability in the North Sea-Baltic Sea area. Geophys. Res. Lett., 34, L14601.

16. Ray, R. D., G. D. Egbert and S. Y. Erofeeva, (2011). Tide Predictions in Shelf and Coastal Waters: Status and Prospects, in Vignudelli, S., A. Kostianoy, P. Cipollini, J. Benveniste (eds.), Coastal Altimetry, Springer, doi:10.1007/978-3-642-12796-0_8

17. Bennett, A. F., (2002). Inverse modeling of the ocean and atmosphere, Cambridge University Press, 346 pp.

18. Hughes, C.W. and M.P. Meredith, (2006). Coherent sea level fluctuations along the global continental slope, Phil. Trans. R. Soc. A, 364, 885-901.

19. Naeije, M., W. Simons, I. Trisirisatayawong and C. Satirapod (2009). GEO2TECDI, Geodetic Earth Observation Technologies for Thailand: Environmental Change Detection and Investigation, OST-ST Meeting Seattle, June 2009, http://www.aviso.oceanobs.com/fileadmin/documents/O STST/2009/poster/Naeije.pdf.

20. Vignudelli, S. \& Co-Authors (2005). Improved satellite altimetry in coastal systems: Case study of the Corsica Channel, Geophys. Res. Lett., 32, L07608. 
21. Durand, F., D. Shankar, F. Birol, and S. S. C. Shenoi (2008). Estimating boundary currents from satellite altimetry: a case study for the East coast of India, $J$. Oceanogr., Vol 64 (no.6), pp 831-845.

22. Durand, F., D. Shankar, F. Birol, and S. S. C. Shenoi (2009). Spatio-temporal structure of the East India Coastal current from Satellite altimetry, J. Geophys. Res., 114, c02013.

23. Vincent, P. \& Co-Authors (2006). AltiKa: a Ka-band altimetry payload and system for operational altimetry during the GMES period, Sensors, vol. 6, pp. 208-234.

24. Stansfield, K. \& Co-Authors (2008). ALTICORE-Africa Royal Society/NRF Workshop Report, Cape Town, April 2008, 13 pp., available from http://www.alticore.eu/africa.

25. Beal, L., Cipollini, P. \& Lutjeharms, J. (2010). "Agulhas Current Time-series (ACT): Towards a multi-decadal index of Agulhas Current transport" in these proceedings (Annex), doi:10.5270/OceanObs09.

26. Oke, P. R., G. B. Brassington, D. A. Griffin and A. Schiller, (2008). The Bluelink Ocean Data Assimilation System (BODAS). Ocean Modelling, 20, 46-70.

27. Schiller, A. \& Co-Authors (2008). Eddy-resolving ocean circulation in the Asian-Australian region inferred from an ocean reanalysis effort. Progr. Ocean., 76, 334-365.

28. Raney, R. K. (1998). The delay Doppler radar altimeter, IEEE Trans. Geosci. Rem. Sens., vol. 36, pp. 1578-1588.

29. Fu, L.-L., and E. Rodriguez (2004). High-resolution measurement of ocean surface topography by radar interferometry for oceanographic and geophysical applications, AGU Geophys. Monogr. 150, IUGG Vol. 19: "State of the Planet: Frontiers and Challenges", R.S.J. Sparks \& C.J. Hawkesworth, eds., 209-224. 